\title{
PENGARUH LITERASI KEUANGAN TERHADAP KINERJA DAN KEBERLANGSUNGAN UMKM DI JAWA TENGAH
}

\author{
Dwitya Aribawa \\ Universitas Atma Jaya Yogyakarta \\ e-mail: dwityaaribawa@mail.uajy.ac.id
}

\begin{abstract}
In facing the ASEAN Economic Community (AEC) 2016, the soundness of good management and finance, and inimitable core competence are one of main keys for SMEs to successfully compete in global market. Creative SMEs are a part of value-addded-based economies that become the main advantage of Indonesia for AECs. Central Java, as one of the provinces with many creative SMEs has a big role for other provinces to benchmark how the development of creative SMEs emerged. This study aims to analyse the effect of financial literacy to creative SMEs' performance and sustainability in Central Jawa. Structural equation model was used to analyse the data. The results confirmed that financial literacy significantly affect creative SMEs' performance and sustainability in Central Java. This implies that good financial literacy can be used to improve appropriate decisions in regard to the efforts of enhancing creative SMEs' performance and sustainability. Thus, it is expected that the government as a regulator, academics as educators, private sector as catalysts can act as triggers for the development of financial literacy for SMEs in Central Java.
\end{abstract}

Kata kunci: financial literacy, performance, sustainability, Creative SMEs http://dx.doi.org/10.20885/jsb.vol20.iss1.art1

\begin{abstract}
Abstrak
Dalam menghadapi Masyarakat Ekonomi ASEAN (MEA) 2016, terwujudnya manajemen yang baik, pengelolaan keuangan yang akuntabel, dan nilai tambah yang otentik merupakan kunci sukses bagi UMKM dalam bersaing di pasar global. UMKM kreatif merupakan bagian tak terpisahkan dari ekonomi bernilai tambah yang menjadi daya saing utama Indonesia untuk MEA 2016. Jawa Tengah sebagai salah satu provinsi yang memiliki berbagai jenis sentra kreatif memiliki peran besar sebagai model acuan bagi provinsi lain dalam pengembangan UMKM. Penelitian ini bertujuan untuk menganalisis pengaruh literasi keuangan terhadap kinerja dan keberlangsungan UMKM di Jawa Tengah. Model persamaan struktural digunakan untuk menganalisis data. Hasil penelitian mengkonfirmasi adanya pengaruh literasi keuangan terhadap kinerja dan keberlangsungan usaha UMKM kreatif di Jawa Tengah. Hal ini memiliki implikasi bahwa dengan literasi keuangan yang baik diharapkan UMKM akan mampu membuat keputusan manajemen dan keuangan yang tepat untuk peningkatan kinerja dan keberlanjutan usaha. Dengan temuan ini diharapkan muncul dukungan yang signifikan dari pemerintah sebagai regulator, akademisi sebagai edukator, swasta sebagai katalisator, dan komunitas sebagai pendorong untuk pengembangan literasi keuangan pada UMKM di Jawa Tengah.
\end{abstract}

Kata kunci: literasi keuangan, kinerja, keberlanjutan usaha, UMKM Kreatif

\section{PENDAHULUAN}

Usaha Mikro Kecil dan Menengah (UMKM) telah lama dipahami memiliki peran signifikan bagi pembangunan ekonomi suatu negara (Audretsch, Van der Horst, Kwaak, dan Thurik, 2009; Carrter dan Jones-Evans, 2006). Secara spesifik, keberadaan UMKM dipercaya akan mampu berkontribusi terhadap upaya pengen- tasan kemiskinan melalui penciptaan lapangan kerja (Carrer dan Klomp, 1996; Adomoko, Danso, dan Damoah, 2016). Atas dasar itu, melalui Paket Kebijakan Ekonomi Tahap IV, pemerintah memberikan kredit permodalan bagi UMKM yang berorientasi ekspor atau terlibat dalam kegiatan yang mendukung ekspor, dengan tingkat bunga yang lebih rendah dibandingkan 
tingkat bunga komersial secara umum (Kementerian Keuangan Republik Indonesia, 2015).

Pemerintah melalui Badan Ekonomi Kreatif (BEK) beranggapan bahwa ekonomi kreatif secara substantif bisa menjadi wujud dari upaya pembangunan ekonomi yang berkelanjutan. Pesan besar yang ditawarkan ekonomi kreatif adalah optimalisasi sumber daya yang bukan hanya terbarukan dan tak terbatas, namun juga ide, talenta dan kreativitas. Arah pengembangan industri kreatif difokuskan pada lapangan usaha budaya kreatif, lapangan usaha kreatif atau hak kekayaan intelektual yang berlangsung secara berkesinambungan dengan kolaborasi dari sektor pemerintah, bisnis, komunitas dan akademisi atau dikenal dengan quad helix (British Council, 2010).

Kementerian Pariwisata dan Ekonomi Kreatif (2014) mengkategorikan industri kreatif di Indonesia ke dalam 15 sub-sektor industri. Sub-sektor industri tersebut adalah; arsitektur, desain, film, video dan fotografi, handicraft, mode/fashion, musik, penerbitan, periklanan, permainan interaktif, riset dan pengembangan, seni pertunjukan, seni lukis dan galeri seni, teknologi informasi, televisi dan radio, serta penambahan sub-sektor kuliner pada tahun 2012. Berdasarkan data dari Kementerian Pariwisata dan Ekonomi Kreatif (2014), sejak tahun 2010 industri kreatif telah berkontribusi pada peningkatan jumlah perusahaan, terutama dari sub-sektor kuliner dan fashion, dan berkontribusi pada Produk Domestik Bruto (PDB) dengan proporsi lebih dari 7\% melalui peningkatan kontribusi ekspor 2011-2013 sebesar total $29,7 \%$.

Secara umum, UMKM sering mengalami keterlambatan dalam pengembangannya. Hal ini dikarenakan berbagai masalah konvensional yang tidak terselesaikan secara tuntas (closed loop problems), seperti masalah kapasitas SDM, kepemilikan, pembiayaan, pemasaran dan berbagai masalah lain yang berkaitan dengan pengelolaan usaha, sehingga UMKM sulit bersaing dengan perusahaan-perusahaan besar (Abor dan Quartey, 2010). Berdasarkan penelitian yang dilakukan oleh Manurung dan Barlian (2012), UMKM di industri kreatif cenderung memiliki orientasi jangka pendek dalam pengambilan keputusan dalam bisnisnya. Hal ini terlihat dari tidak adanya konsep inovasi yang berkelanjutan dan aktivitas inti bisnis yang tidak konsisten. Pada akhirnya, pengem- bangan kinerja jangka panjang UMKM yang bergerak pada industri kreatif cenderung stagnan dan tidak terarah dengan baik.

Oleh karena itu, diperlukan upayaupaya strategis guna meningkatkan kinerja dan keberlangsungan UMKM. Salah satu cara yang dapat dilakukan adalah dengan memperkaya pengetahuan pelaku UMKM terhadap pengetahuan keuangan sehingga pengelolaan dan akuntabilitasnya bisa dipertanggungjawabkan dengan lebih baik sebagaimana layaknya perusahaan besar. Literatur telah banyak yang mengkonfirmasi bahwa kemampuan perusahaan dalam mengenali dan mengakses sumber daya keuangan akan berdampak pada tingkat pertumbuhan perusahaan (Binks dan Ennew, 1996; Bygrave dan Zacharakis, 2008; Grande, Madsen, dan Borch, 2011; Adomoko et al., 2016). Dalam menghadapi Masyarakat Ekonomi ASEAN (MEA) 2016, UMKM yang "dewasa" secara manajemen dan "kuat" dalam pengelolaan keuangan diharapkan mampu menjadi kunci utama Indonesia dalam bersaing di pasar global.

Data terbaru yang dipaparkan oleh OJK, sebagaimana yang dikutip oleh Soetiono (2013) mengungkapkan bahwa hanya responden dari sektor perbankanlah yang memiliki literasi keuangan yang tinggi dibandingkan sektor-sektor lain. Sedangkan survei yang dilakukan oleh Grup Pengembengan Keuangan Inklusif (2014) menemukan bahwa aksesibilitas bukan satu-satunya faktor yang menyebabkan responden tidak berhubungan dengan bank. Sampai saat ini, belum ada penelitian atau survei di Indonesia yang secara spesifik melihat tingkat literasi keuangan untuk perusahaan dari sudut pandang pemilik dan atau pengelola (manajer) perusahaan.

Penelitian ini bertujuan untuk menganalisis dampak literasi keuangan (financial literacy) terhadap kinerja dan keberlanjutan UMKM kreatif di Jawa Tengah. Penelitian ini diharapkan dapat memberikan masukan pada stakeholders mengenai pentingnya peningkatan literasi keuangan bagi pelaku usaha, khususnya UMKM kreatif.

\section{TINJAUAN LITERATUR}

\section{Literasi Keuangan}

The Association of Chartered Certified Accountants (2014) merumuskan bahwa kon- 
sep literasi keuangan mencakup pengetahuan mengenai konsep keuangan, kemampuan memahami komunikasi mengenai konsep keuangan, kecakapan mengelola keuangan pribadi/perusahaan dan kemampuan melakukan keputusan keuangan dalam situasi tertentu. Lusardi (2012) menyatakan bahwa literasi keuangan terdiri dari sejumlah kemampuan dan pengetahuan mengenai keuangan yang dimiliki oleh seseorang untuk mampu mengelola atau menggunakan sejumlah uang untuk meningkatkan taraf hidupnya. Literasi keuangan sangat terkait dengan perilaku, kebiasaan dan pengaruh dari faktor eksternal.

Berdasarkan PISA 2012: Financial Literacy Assessment Framework (OECD INFE, 2012), dirumuskan bahwa literasi keuangan merupakan faktor yang fundamental untuk pertumbuhan ekonomi dan stabilitas keuangan. Dari sudut pandang konsumen, literasi keuangan yang baik akan memunculkan keputusan pembelanjaan yang mengedepankan kualitas. Hal ini akan berakibat pada kompetisi di industri yang menjadi sehat dan kompetisi akan mengedepankan inovasi dalam barang dan jasa yang ditawarkan ke konsumen. Selain itu, dengan literasi keuangan yang baik juga bisa meminimalkan terjadinya keputusan yang salah terhadap isu ekonomi dan keuangan yang muncul. Dari sudut pandang penyedia jasa keuangan, literasi keuangan yang baik akan memberikan informasi yang memadai mengenai produk, pemahaman resiko pada pelanggan dan efisiensi biaya. Sedangkan dari sudut pandang pemerintah, dengan adanya literasi keuangan yang baik pada masyarakat maka pemerintah dapat memperoleh pemasukan pajak dengan maksimal untuk pengembangan infrastruktur dan fasilitas pelayanan publik.

UMKM sebagai penggerak sektor informal terbesar di Indonesia dengan jumlah serapan pekerja terbanyak mempunyai peran penting dalam sistem ekonomi. Menurut Cole, Sampson, dan Zia (2010), cara tercepat untuk menggerakkan ekonomi di emerging market adalah dengan memberikan fokus pengembangan sektor informal (UMKM) yang akan berdampak pada meningkatnya tingkat pendapatan kelas menengah.

Tingkat literasi keuangan dari sudut pandang perorangan atau keluarga dapat memiliki dampak pada kemampuan untuk memiliki tabungan jangka panjang yang digunakan untuk memiliki aset (seperti tanah atau rumah), pemenuhan pendidikan tinggi dan dana hari tua (pensiun). Pengelolaan uang yang tidak efektif akan berdampak pada krisis keuangan keluarga (Braunstein and Welch, 2002). Temuan tersebut juga dapat diadaptasi untuk perusahaan.Dalam hal ini, UMKM yang memiliki literasi keuangan yang baik akan dapat mencapai tujuan perusahaannya, memiliki orientasi pengembangan usaha dan mampu survive dalam kondisi ekonomi yang sulit.

Di dalam literatur bisnis dan kewirausahaan, kurangnya pengetahuan dan akses terhadap sumber daya keuangan telah dihubungkan dengan ketidakmampuan perusahaan dalam mencapai tujuan (Beck, DemirgucKunt, dan Maksimovic, 2005; Hutchinson dan Xavier, 2006; Malo dan Norus, 2009; serta Coad dan Tamvada, 2012), dan ketidakleluasaan manajer dalam mengambil tindakan strategis (Wiklund dan Shepherd, 2003). Literatur yang lain juga menegaskan bahwa literasi dan inklusi keuangan akan mampu meningkatkan pertumbuhan perusahaan (Cooper, Gimeno-Gascon, dan Woo, 1994; Storey, 1994; Forbes Insights, 2011).

Pada penelitian ini pengukuran literasi keuangan pada UMKM mengacu pada proyek kolaboratif yang diberi nama Support for Economic Analysis Development in Indonesia (SEADI) yang dilakukan oleh Definit, Otoritas Jasa Keuangan (OJK) dan USAID (2013). Dimana dari proyek tersebut dihasilkan temuan yang dinamakan Indonesian Basic Financial Literacy Index. Pertanyaan pada index tersebut dimodifikasi untuk kesesuaian dengan unit penelitian yaitu UMKM (lampiran 2). Salah satu contoh pertanyaan pada kuesioner adalah "Bila bank tempat Anda membuka rekening atas nama perusahaan tersebut mengalami kebangkrutan, apakah pemerintah akan menjamin sejumlah dana yang tersimpan pada rekening tersebut?".

\section{Kinerja dan Keberlanjutan UMKM}

Pada kompetisi global, perusahaan diharapkan mampu memberikan nilai tambah lebih pada barang/jasa yang ditawarkan baik itu secara kualitas (yang lebih baik) ataupun efisien (lebih tepat guna) daripada pesaing. Hal ini secara spesifik sulit dilakukan oleh UMKM, dikarena- 
kan minimnya kemampuan manajemen dan pengelolaan modal kerja yang terbatas. Meskipun dengan keterbatasan tersebut, namun UMKM cenderung memiliki ketahanan (kinerja yang stabil) terhadap perubahan iklim bisnis dan ekonomi (Ali, 2003).

Ali (2003) mengemukakan kinerja UMKM dianalisis dengan menggunakan pendekatan yang didasarkan pada tiga asumsi berikut, yaitu: 1) Pengukuran kinerja UMKM kerap sulit dilakukan secara kuantitatif, dikarenakan terbatasnya sumber daya (pemahaman keuangan dan tenaga kerja). 2) Pengukuran kinerja pada umumnya melihat indikator keuangan yang kompleks, sehingga hal ini tidak secara lengkap memperlihatkan kondisi aktual yang terjadi di bisnis tersebut. 3) Pengukuran kinerja yang kerap dipakai relatif hanya sesuai bila digunakan untuk perusahaan besar yang terstruktur dalam manajemen perusahaannya.

Maka dirumuskan pendekatan non-cost performance measures untuk mengukur kinerja UMKM sebagai pengukuran kinerja keuangan dan non keuangan UMKM. Dengan pengukuran yang mudah (melalui persepsi) diharapkan mampu memperlihatkan kondisi sebenarnya dari UMKM tersebut, di samping ke depan perlu dilakukan edukasi untuk menghitung kinerja perusahaan dengan indikator yang mudah seperti company's growth, company's total revenue (sales), total orders dan cash position.

Keberlanjutan usaha (business sustainability) pada UMKM dilihat dari keberhasilan perusahaan dalam melakukan inovasi, pengelolaan karyawan dan pelanggan serta pengembalian terhadap modal awalnya. Dimana hal ini memperlihatkan bahwa perusahaan memiliki orientasi untuk berkembang dan melihat peluang untuk inovasi secara berkesinambungan (Hudson, Smart and Bourne, 2001).

Pada penelitian ini, pengukuran kinerja dan keberlanjutan usaha pada UMKM mengacu pada pendekatan persepsi kinerja bisnis yang diadaptasi dari Balance Score Card (Kaplan and Norton, 2005; Hudson et al., 2001). Salah satu contoh pernyataan pada kuesioner adalah "Perusahaan mampu dengan baik mengantisipasi (meningkatkan) jumlah produksi apabila permintaan meningkat".

\section{Literasi Keuangan, Kinerja dan Keberlanju- $\tan$ UMKM}

Dengan literasi keuangan yang baik pengusaha mampu untuk menggunakan kemampuan di bidang keuangan dalam pengambilan berbagai keputusan yang tepat untuk perusahaan mereka (Muraga dan John, 2015). Pemilik/pengelola bisnis sangat terkait dengan pengambilan keputusan keuangan yang kompleks dan strategis terkait dengan keberhasilan mencapai tujuan dan keberlanjutan usaha (Draxler, Fischer, dan Schoar, 2014).

Penelitian sebelumnya oleh Dahmen and Rodríguez (2014) menemukan bahwa terdapat hubungan yang bermakna antara literasi keuangan dan kinerja yang dialami pengusaha. Hubungan ini secara logis diterapkan pada perusahaan yang dengan literasi keuangan baik akan mampu secara strategis mengidentifikasi dan merespon perubahan iklim bisnis, ekonomi dan keuangan sehingga keputusan yang diambil akan menciptakan solusi inovatif dan terarah dengan baik untuk peningkatan kinerja dan keberlanjutan usaha. Model penelitian dapat dilihat pada gambar 1 .

Secara umum, hipotesis yang ingin diuji pada penelitian ini adalah sebagai berikut:

H1: Literasi keuangan memiliki pengaruh yang signifikan terhadap kinerja UMKM di Jawa Tengah

$\mathrm{H} 2$ : Literasi keuangan memiliki pengaruh yang signifikan terhadap keberlangsungan UMKM di Jawa Tengah.

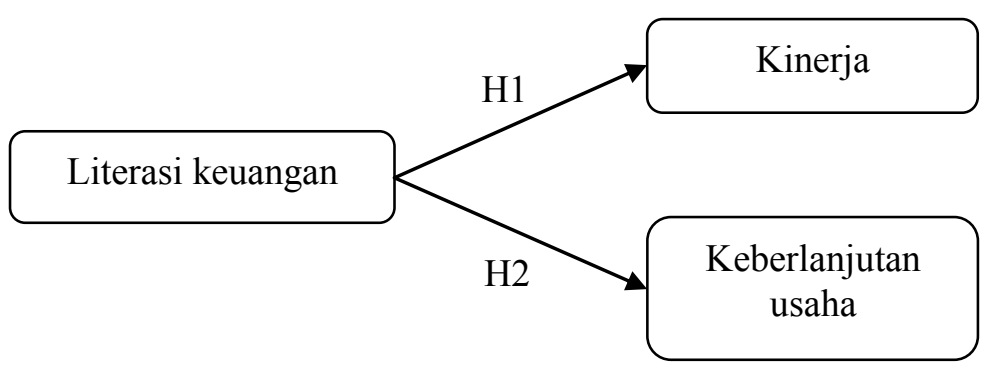

Gambar 1: Model Penelitian 


\section{METODE PENELITIAN}

\section{Desain Penelitian}

Cross sectional study digunakan untuk menganalisis input dari penelitian ini dalam rentang waktu pengambilan sampel. Objek penelitian ini adalah pemilik dan pengelola (manajer) dari bisnis yang bergerak di salah satu sub-sektor industri kreatif dengan skala bisnis mikro, kecil atau menengah yang berlokasi di provinsi Jawa Tengah. Tiga kota (Kota Yogyakarta, Surakarta dan Magelang) dipilih karena menjadi pionir dan unggul dalam pengembangan industri kreatif di Indonesia. Hal tersebut tercermin dalam Indeks Kekuatan Daerah Kreatif yang memperlihatkan kota tersebut memiliki indeks lebih dari 30, dimana index tersebut mengindikasikan kota tersebut sebagai daerah kreatif dengan pertumbuhan tinggi di Provinsi Jawa Tengah (Litbang Kompas, 2014). Selain tiga kota tersebut, Kota Salatiga dan Semarang juga diikutsertakan pada penelitian ini dengan pertimbangan karena memiliki fokus pada sektor industri kreatif, meskipun belum terindeks oleh Kompas.

\section{Populasi dan Sampel Penelitian}

Kementerian Pariwisata dan Ekonomi Kreatif (2014) mengklasifikasikan bisnis kreatif di Indonesia ke dalam 15 sub-sektor, yaitu arsitektur, desain, kerajinan, kuliner, mode, penerbitan dan percetakan, periklanan, permainan interaktif, riset dan pengembangan, seni pertunjukan, seni rupa, teknologi informasi, televisi dan radio. Mengacu pada data Kementerian Perdagangan (2008), total jumlah bisnis kreatif di Indonesia adalah sekitar tiga juta dengan perkembangan $3-4 \%$ per tahun, dan sekitar 90\% dari bisnis tersebut adalah UMKM. Data yang dimiliki Kementerian Koperasi dan UKM pada tahun 2012 mengungkapkan bahwa jumlah UMKM kreatif di seluruh Kabupaten/Kota di Provinsi Jawa Tengah adalah sebanyak 80.583 UMKM. Jumlah ini sekaligus merupakan jumlah populasi UMKM yang dianalisis dalam penelitian ini.

Metode pengambilan sampel yang digunakan adalah purposive sampling, dengan kriteria sebagai berikut: 1) Memiliki keunikan (menawarkan produk atau jasa lebih dari satu macam). 2) Beroperasi atau memiliki kantor pusat di cakupan wilayah penelitian.
Responden dari penelitian ini adalah individu yang memahami dan ikut dalam proses pengembangan strategis dari perusahaan. Pada UMKM, pemilik (owner) relatif banyak mengambil peran dalam keputusan strategis. Namun tidak menutup kemungkinan ada manajer yang juga menjadi person in charge pada UMKM tertentu. Satu sampel merepresentasikan satu UMKM. Apabila ada dua responden dalam satu perusahaan maka data akan diambil secara rata-rata.

Pengambilan sampel dalam penelitian hanya berasal dari empat kota, yaitu Yogyakarta, Magelang, Surakarta dan Semarang. Sebagian besar responden berasal dari perusahaan yang ada pada database resmi dari Kementerian Pariwisata dan Ekonomi Kreatif pada situs www.directory.indonesiakreatif.net.

\section{Metode Pengumpulan Data}

Metode pengumpulan data primer dilakukan dengan kuesioner secara online dan tatap muka secara langsung dengan responden. Kuesioner terdiri dari pertanyaan demografis dan pertanyaan penelitian terstruktur. Pertanyaan terstruktur terdiri dari dua kategori pertanyaan, pertama yaitu tipe quiz yang dimodifikasi dari Basic Indonesian Financial Literacy Index (Definit, OJK and USAID, 2013) untuk mengetahui literasi keuangan pada UMKM. Sedangkan kategori kedua adalah modifikasi dari Hudson et al. (2001) yang melakukan pengukuran kinerja berdasarkan persepsi dengan modified likert-type dengan skala pengukuran 5 ( $1=$ sangat tidak setuju, $3=$ netral, dan $5=$ sangat setuju). Sementara keberlanjutan usaha dilihat dari kemampuan inovasi, pengelolaan karyawan dan pelanggan serta pengembalian terhadap modal awalnya. Kuesioner ditujukan kepada pemilik atau manajer UMKM kreatif. Secara umum, konstruk dan indikator yang digunakan tersaji sebagaimana di Tabel 1.

\section{Teknik Analisis}

Data terkumpul dianalisis menggunkana model persamaan struktural berbasis partial least square. Software Smart PLS 3.0 digunakan untuk membantu menganalisis hubungan antar variabel. Analisis deskriptif digunakan untuk interpretasi data responden, sementara model persamaan struktural untuk menguji hipotesis. 
Tabel 1. Konstruk dan Indikator Penelitian

\begin{tabular}{ll}
\hline Konstruk & Indikator \\
\hline Literasi Keuangan & 1. Kepemilikan rekening atas nama perusahaan \\
& 2. Identifikasi perusahaan saat pembukaan rekening \\
3. Setoran dana minimal saat pembukaan rekening \\
4. Pengetahuan tentang jaminan tabungan \\
5. Kepahaman tentang potensi imbal hasil tabungan dalam satu tahun \\
6. Kepahaman tentang potensi imbal hasil tabungan dalam multi tahun \\
7. Kepahaman tentang perhitungan bunga kredit per tahun \\
8. Pengetahuan tentang premidi antara dua pilihan produk \\
9. Pengetahuan tentang pengaruh inflasi terhadap nilai uang \\
10. Pengetahuan tentang nilai waktu uang \\
1. Kepahaman tentang pengaruh inflasi terhadap pertumbuhan perusahaan \\
1. Adanya pekerjaan yang terencana dan berjalan sesuai rencana kerja \\
2. Seringnya terjadi kesalahan kerja yang menyebabkan pengulangan \\
3. Adanya pertumbuhan penjualan \\
4. Adanya penurunan biaya tetap \\
5. Kemampuan antisipasi produksi apabila permintaan meningkat \\
6. Jaminan ketepatan waktu pada pelanggan \\
(sustainability) & 7. Kesesuaian produk dengan spesifikasi yang ditawarkan \\
& 1. Telah tercapainya BEP \\
\hline Sulangan & 2. Terdapat sistem pelacakan kepuasan konsumen \\
& 3. Terdapat sistem pelacakan kepuasan karyawan/manajer
\end{tabular}

Sumber: Data diolah

\section{HASIL PENELITIAN DAN PEMBAHASAN}

\section{Deskripsi Statistik Obyek Penelitian}

Penelitian ini ditujukan untuk UMKM yang beroperasi pada salah satu dari 15 sub-sektor bisnis kreatif. Sampai 18 November 2015, responden dari penelitian ini terdiri dari 33 UMKM kreatif yang mewakili beberapa dari 15 subsektor industri kreatif. Sebagian besar responden (67\%) pada penelitian ini berstatus pemilik UMKM kreatif. Seluruh responden menyatakan dirinya memiliki kapabilitas untuk menjawab pertanyaan terkait strategi perusahaan.

Berdasarkan ukuran bisnis, penelitian ini mengacu pada kriteria Badan Pusat Statistik (BPS) Republik Indonesia yang mengkategorikan UMKM berdasarkan jumlah karyawan.Terdapat 55\% UMKM yang merupakan usaha kecil (memiliki 5-19 karyawan) pada penelitian ini. Sedangkan usaha kecil dan usaha menengah berturut-turut adalah 36\% dan 9\% dari total responden penelitian.

Dilihat dari lama beroperasi UMKM, sejumlah 42\% UMKM dari penelitian ini telah beroperasi antara 1-3 tahun. Menariknya, terdapat 9\% UMKM yang menjadi responden dikategorikan menjadi start-up business, dimana perusahaan tersebut beroperasi kurang dari satu tahun. Dari analisis deskriptif juga diketahui bahwa rata-rata indeks literasi keu- angan responden pada penelitian ini adalah $67 \%$, dimana jumlah ini ada di area moderat untuk tingkat literasi keuangan (basic). Sedangkan dari aspek kinerja, responden memperlihatkan nilai yang cukup baik (3.62) dan untuk aspek keberlanjutan UMKM Kreatif memperlihatkan nilai yang cukup (3.14). Data deskriptif secara lengkap dapat dilihat pada tabel 2.

\section{Pengujian Hipotesis}

Dalam pengujian rancangan model penelitian ini diajukan uji pada dua hipotesis sebagai berikut:

H1: Literasi keuangan memiliki pengaruh yang signifikan terhadap kinerja UMKM

$\mathrm{H} 2$ : Literasi keuangan memiliki pengaruh yang signifikan terhadap keberlanjutan UMKM

Variabel Literasi Keuangan (FL) merupakan variabel independen laten yang dikonstruksi dengan 11 pertanyaan. Sedangkan variabel Kinerja (Perf) dan Keberlanjutan usaha (Sust) terdiri dari masing-masing tujuh dan tiga konstruk pernyataan/pertanyaan. Melalui proses kerja Smart PLS versi 3.0 dapat diketahui besaran nilai indikator yang mencerminkan validitas variabel (loadings of reflective indicators), seperti terlihat pada Gambar 2. 
Tabel 2. Data Deskriptif Penelitian

\begin{tabular}{lcc}
\hline Memiliki Rekening Perusahaan & $33 \%$ (Rendah) \\
Rata-rata Literasi Keuangan & \multicolumn{2}{c}{$67 \%$ (Moderat) } \\
Rata-rata Kinerja & 3.61 (Cukup Baik) \\
Rata-rata Keberlanjutan usaha & 3.14 (Cukup) \\
Usia Bisnis & Jumlah UMKM & Persentase \\
Start-up & 3 & $9 \%$ \\
1-3 Tahun & 14 & $42 \%$ \\
4-5 Tahun & 10 & $30 \%$ \\
Lebih dari 5 Tahun & 6 & $18 \%$ \\
Total & 33 & $100 \%$ \\
Ukuran usaha & Jumlah UMKM & Persentase \\
Usaha Mikro & 12 & $36 \%$ \\
Usaha Kecil & 18 & $55 \%$ \\
Usaha Menengah & 3 & $9 \%$ \\
Total & 33 & $100 \%$ \\
Domisili Usaha & Jumlah UMKM & Persentase \\
Yogyakarta & 19 & $58 \%$ \\
Solo & 6 & $18 \%$ \\
Magelang & 2 & $6 \%$ \\
Semarang & 6 & $18 \%$ \\
Total & 33 & $100 \%$ \\
Posisi di Usaha & 22 & $67 \%$ \\
Owner/Pemilik & 10 & $30 \%$ \\
Pengelola/Manajer & 1 & $3 \%$ \\
Pemegang saham & 33 & $100 \%$ \\
Total & & \\
Sula & Jumlah Responden & Persentase \\
\hline
\end{tabular}

Sumber: Data diolah

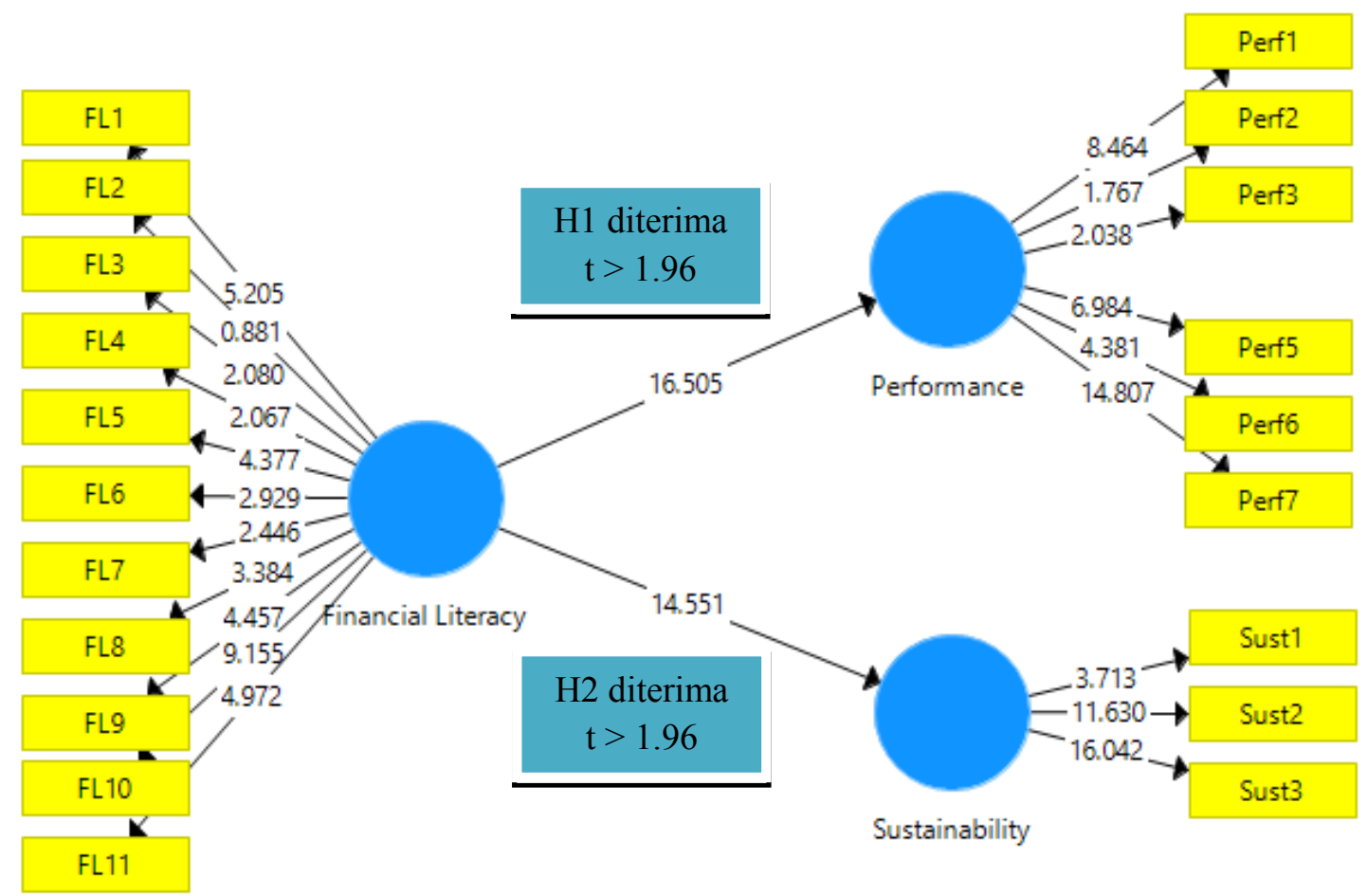

Gambar 2. Output analisis Model Smart PLS 
Berdasarkan hasil analisis bootstrapping pertama dari Smart PLS 3.0, terdapat indikator pengukuran kinerja (per f4) dengan nilai loading $\leq 0.5$ (terlihat pada lampiran 1). Model diketahui tidak valid, maka dilakukan analisis ulang dengan eksklusi pengukuran per f4. Setelah dilakukan analisis bootstrapping kedua, didapatkan model yang memiliki seluruh nilai loading $\geq 0.5$ dengan dan nilai $\mathrm{R}^{2}$ sebesar 0.74 (tabel di lampiran 1) dengan kategori moderat atau sedang (Hair, Black, Babin and Anderson, 2010). Berdasarkan validitas konvergen (lampiran 1), semua indikator memiliki nilai $\mathrm{CR}>$ 0,7 dan AVE value $\geq 0.5$, demikian juga untuk validitas diskriminan, semua nilai square root (AVE) > inter-constract correlation.

Pengujian model struktural untuk menilai efek dari setiap arah hubungan (causal path) dan pengujian hipotesis yang telah ditetapkan, digunakan teknik bootstrapping. Berdasarkan hasil analisis teknik tersebut, semua arah hubungan variabel signifikan pada tingkat signifikan ( $p$ value) $5 \%$ dan dengan nilai t-statistik masing-masing adalah $>1,96$. Hubungan antarvariabel terlihat pada inner model menunjukkan seluruh hipotesis yang diajukan dapat diterima.

\section{Diskusi dan Pembahasan}

Dari pengujian hipotesis dengan metode bootstrapping partial least square menggunakan software Smart PLS 3.0 diketahui bahwa terdapat pengaruh yang signifikan dari literasi keuangan terhadap kinerja dan keberlanjutan UMKM. Hasil ini sekaligus mengkonfirmasi penelitian sebelumnya yang dilakukan oleh Dahmen dan Rodríguez (2014), Fatoki (2014), Wise (2013), serta Adomako et al, (2016). Secara umum, penelitian mereka menyatakan bahwa bila pengusaha di sektor UMKM (dalam penelitian ini UMKM industri kreatif) memiliki kemampuan literasi keuangan yang memadai, maka keputusan bisnis dan keuangan yang diciptakan akan menuju ke arah pengembangan yang membaik dari waktu ke waktu, meningkatkan kemampuan usaha untuk bertahan di tengah krisis dan pada akhirnya akan membuat bisnis tersebut memiliki keberlanjutan jangka panjang. Namun begitu, hasil penelitian ini tampak kontradiktif dengan hasil penelitian Eke dan Raath (2013) yang menemukan bukti bahwa literasi keuangan pemilik pada UMKM di Provinsi Gauteng, Afrika Selatan, tidak berhubungan dengan kinerja dan pertumbuhan UMKM.

UMKM memiliki karakteristik yang cukup unik untuk menghadapi perubahan lingkungan bisnis dan stakeholders. Sektor bisnis ini cenderung untuk lebih bekerjasama daripada berkompetisi dalam hubungan antar pelaku usahanya (Kumar, Boesso, Favotto, dan Menini, 2012). Knowledge sharing ke UMKM terjadi tidak hanya dari pemerintah, akademisi, atau bisnis besar saja, namun knowledge sharing antar UMKM bisa menjadi kunci utama keberhasilan UMKM dalam berkembang di era perdagangan global. Sangat penting untuk menyadari diperlukan kerjasama intraUMKM untuk mencapai kemampuan yang saling melengkapi.

Munculnya gerakan komunitas pengusaha muda ataupun pengusaha kreatif bisa menjadi sebuah bukti bahwa UMKM berupaya untuk enabling smallness untuk memperoleh keuntungan dari kolaborasi, knowledge sharing dan channel sharing yang terjadi di komunitas tersebut. Konsep triple helix yang digunakan pemerintah sebagai landasan untuk pengembangan ekonomi kreatif 2025 kini telah berkembang menjadi pendekatan quad-helix dimana komunitas menjadi elemen penting di samping sektor pemerintah, sektor bisnis dan sektor akademisi atau universitas sebagai perwujudan perkembangan, penentu arah kebijakan dan menjaga lingkungan bisnis agar tetap kuat dan mampu bersaing di pasar global.

\section{KESIMPULAN DAN SARAN}

\section{Kesimpulan}

Hasil riset ini masih berlangsung sehingga kesimpulan sangat bersifat parsial. Secara umum diketahui bahwa terdapat pengaruh literasi keuangan terhadap kinerja dan keberlanjutan usaha pada UMKM kreatif di Jawa Tengah. Dengan kecenderungan untuk mengatasi keterbatasan yang dimiliki, UMKM memiliki karakteristik kooperatif dalam menjalankan bisnisnya untuk saling melengkapi keterbatasan dan memperoleh keunggulan kompetitif yang spesifik untuk bersaing di lingkungan global.

\section{Implikasi Manajerial}

Dengan demikian, ada tantangan besar bagi pelaku UMKM kreatif untuk memiliki penge- 
tahuan lebih mengenai literasi keuangan. Dimana dengan meningkatnya literasi keuangan, pemilik dan atau pengelola UMKM diharapkan mampu membuat keputusan manajemen dan keuangan yang tepat untuk keberhasilan dan keberlanjutan usaha.

Penelitian ini juga memberikan insight untuk stakeholder yang memiliki peran untuk meningkatkan tingkat literasi keuangan di Indonesia. Dalam hal ini Pemerintah (BI, OJK dan Kementerian terkait) hendaknya sebagai aggregator atau fasilitator untuk sharing knowledge mengenai literasi keuangan antar UMKM (sharing sukses pengusaha berhasil dengan literasi keuangan yang baik), UMKM dengan akademisi, UMKM dengan komunitas terkait serta UMKM dengan pihak swasta nasional (sektor jasa keuangan ataupun non keuangan). Dengan terbentuknya komunitas UMKM yang memiliki literasi keuangan yang baik, diharapkan berbagai bentuk program dan insentif dari pemerintah dapat diserap (digunakan) dengan optimal dan bertanggung jawab oleh para pengusaha.

Di samping itu, penelitian ini juga dapat menjadi acuan bagi Badan Ekonomi Kreatif untuk melihat bahwa literasi keuangan bisa menjadi salah satu hal penting yang dapat mendukung dengan road map Penegembangan Ekonomi Kreatif 2025.

\section{Saran Untuk Penelitian Akan Datang}

Penelitian mengenai literasi keuangan untuk perusahaan (UMKM dan usaha besar) masih realtif jarang dilakukan di Indonesia. Sebagian besar penelitian melihat hubungan atau pengaruh literasi keuangan individu ataupun keluarga. Penelitian pada industri kreatif sendiri masih sangat terbatas. Adanya badan ekonomi kreatif mengindikasikan bahwa industri ini memiliki peran yang penting dalam perkeonomian Indonesia. Di masa yang akan datang, diharapkan muncul banyak riset-riset dengan perspektif yang lebih aplikatif untuk pengembangan bisnis kreatif di Indonesia. Penyempurnaan terhadap penelitian ini dapat dilakukan di antaranya dengan cara memperluas cakupan sampel menjadi lebih luas, memodifikasi model menjadi lebih kompleks, atau bisa juga dengan memperluas cakupan indikator pengukur.

\section{DAFTAR PUSTAKA}

Abor, J., dan P. Quartey. 2010. Issues in SME development in Ghana and South Africa. International Research Journal of Finance and Economics. 39 (6). 219-227.

Adomoko, S., Danso, A., dan Damoah, J.O. 2016. The moderating influence of financial literacy on the relationship between access to finance andfirm growth in Ghana. Venture Capital. 18(1). 43-61.

Ali, I. 2003. A Performance Measurement Framework for a Small and Medium Enterprise. Univerity of Alberta Dissertation.

Audretsch, D., Van der Horst, R., Kwaak, T., dan Thurik, R. 2009. First section of the annual report on EU small and medium-sized enterprises. EIM Business \& Policy Research. 12.

Beck, T., A. Demirguc-Kunt, dan V. Maksimovic. 2005. Financial and legal constraints to growth: Does firm size matter?. The Journal of Finance. 60 (1). $137-177$

Binks, M. R., dan C. T. Ennew. 1996. Growing firms and credit constraints. Small Business Economics. 8. 17-25.

Braunstein, S.,dan Welch, C. 2002. Financial Literacy: An Overview of Practice, Research, and Policy. USA: Federal Reserve Bulletin.

British Council. 2010. Mapping the Creative Industries: A Toolkit. London. The British Council.

Bygrave, W. D., dan A. Zacharakis. 2008.

Entrepreneurship. New York. Wiley.

Carrer, M., and L. Klomp. 1996. Small business and job creation: A comment. Small Business Economics. 8(4). 17322.

Carter, S., dan Jones-Evans, D. 2006. Enterprise and Small Business. Harlow. FT Prentice-Hall.

Coad, A., dan J. P. Tamvada. 2012. Firm growth and barriers to growth among 
small firms in India. Small Business Economics. 39. 383-400.

Cole, S., Sampson, T., dan B. Zia. 2010. Prices or knowledge? what drives demand for financial services in emerging markets?. Harvard Business School Working Paper. 09-117.

Cooper, A. C., F. J. Gimeno-Gascon, dan C. Y. Woo. 1994. Initial human and financial capital as predictors of new venture performance. Journal of Business Venturing. 9(5). 371-395.

Dahmen, P., dan Rodríguez, E. 2014. Financial literacy and the success of small businesses: An observation from a small business development center. Numeracy. 7(1). 3.

Definit, OJK,dan USAID. 2013. Developing Indonesian Financial Literacy Index. Jakarta. USAID.

Draxler, A., Fischer, G., dan Schoar, A. 2014. Keeping it simple: Financial literacy and rules of thumb. American Economic Journal: Applied Economics. 6(2). 1-31.

Eke, E., dan Raath. 2013. SMME owners' financial literacy and business growth. Mediterranean Journal of Social Sciences. 4(13). 397-406.

Fatoki, O. 2014. The financial literacy of micro entrepreneurs in South Africa. Journal of Social Science. 40(2). 151 - 158.

Forbes Insights. 2011. Nurturing Europe's Spirit of Enterprise. http://www.accaglobal.co.uk/content/d am/acca/global/PDFtechnical/smallbusiness/europe insight sfin2.pdf . Diakses tanggal 20 Juni 2015.

Grande, J., E. L. Madsen, dan O. J. Borch. 2011. The relationship between resources, entrepreneurial orientation and performance in farm-based ventures. Entrepreneurship \& Regional Development:An International Journal. 23(3). 89-111.
Grup Pengembangan Keuangan Inklusif. 2014. Financial Literacy Baseline Survey (FLBS). Jakarta. GPKI -DPAU.

Hair, JF., WC. Black, WJ. Babin and RE. Anderson. 2010. Multivatiate Data Analysis, 7th Edition. New Jersey. Pearson Prentice Hall.

Hudson, M., A. Smart and M. Bourne. 2001. Theory and practice in SME performance measurement systems. International Journal of Operations \& Production Management. 21(8). 10961115.

Hutchinson, J., dan A. Xavier. 2006. Comparing the impact of credit constraints on the growth of SMEs in a transition country with an established market economy. Small Business Economics. 27 (2/3). 169-179.

Kaplan, R.S, dan Norton, D.P. 2005. The balanced scorecard - Measures that drive performance. Harvard Business Review. 83(7). 172.

Kementerian Keuangan Republik Indonesia. 2015. Melalui Paket Kebijakan Ekonomi Tahap IV Pemerintah Dukung UMKM Berorientasi Ekspor. http://www.kemenkeu.go.id/Berita/mel alui-paket-kebijakan-ekonomi-tahapiv-pemerintah-dukung-umkmberorientasi-ekspor . Diakses tanggal 22 Oktober 2015.

Kementerian Pariwisata dan Ekonomi Kreatif. 2014. Tim Studi Ekonomi Kreatif:Kontribusi Ekonomi Kreatif Indonesia.

http://gov.indonesiakreatif.net/kontribu si-ekonomi-kreatif-indonesia/. . Diakses tanggal 28 Oktober 2015.

Kementerian Perdagangan. 2008. Pengembangan Ekonomi Kreatif Indonesia 2025. Jakarta. Kementerian Perdagangan Republik Indonesia.

Kumar, K., Boesso, G., Favotto, F., dan Menini, A. 2012. Strategic orientation, innovation patterns and performances of SMEs and large companies. Journal of Small Business and Enterprise Development. 19 (1). 132 - 145. 
Litbang Kompas. 2014. Special Report: Indeks Kekuatan Daerah Kreatif . Jakarta: Kompas. 27 Oktober 2014.

Lusardi, A. 2012. Numeracy, financial literacy, and financial decision-making (No. w17821). National Bureau of Economic Research.

Malo, S., dan J. Norus. 2009. Growth dynamics of dedicated biotechnology firms in transition economies. Evidence from the Baltic countries and Poland. Entrepreneurship and Regional Development. 21 (5). 481-502.

Manurung, E.M., dan Barlian, I. 2012. From small to significant: Innovation process in small-medium creative businesses. International Journal of Innovation, Management and Technology. 3(6). $788-792$.

Muraga, K.P, dan John, N. 2015. Effects of financial literacy on performance of youth led entreprises: a case of equity group foundation training program in Kiambu county. International Journal of Social Sciences Management and Entrepreneurship. 2(1) 218-231.

OECD INFE. 2012. PISA 2012 Literacy assessment framework. [Report Paper]

Soetiono, K.S. 2013. Financial Literacy in Indonesia and The National Strategy. Hongkong. Citi-FT Financial Times Education Summit.

Storey, D. J. 1994. Understanding the Small Business Sector. London: Routledge.

The Association of Chartered Certified Accountants. 2014. Financial education for entrepreneurs: what next?. [Report Paper].

Wiklund, J., H. Patzelt, dan Dean A. S. 2009. Building an integrative model of small business growth." Small Business Economics. 32. 351-374.

Wise, S. 2013. The impact of financial literacy on new venture survival. International Journal of Business and Management. 8 (23). 30 - 39. 


\section{Adjusted R-Square Model}

\section{LAMPIRAN 1. Output Smart PLS 3.0}

\section{R Square Adjusted}

\begin{tabular}{|c|c|c|c|c|c|c|}
\hline \multicolumn{2}{|c|}{ Mean, STDEV, T-Values, P-Val... } & \multicolumn{2}{|c|}{ Confidence Intervals } & \multicolumn{2}{|c|}{ 周 Confidence Intervals Bias Cor... } & \multirow{2}{*}{$\begin{array}{c}\text { Samples } \\
\text { P Values }\end{array}$} \\
\hline & Original Sampl... & Sample Mean (... & Stanc & dard Error ... & T Statistics $(\mid \mathrm{O} \ldots$. & \\
\hline Performance & 0.881 & 0.886 & & 0.066 & 13.353 & 0.000 \\
\hline Sustainability & 0.744 & 0.769 & & 0.107 & 6.944 & 0.000 \\
\hline
\end{tabular}

\section{Composite Reliability (CR) Model}

\section{Composite Reliability}

Mean, STDEV, T-Values, P-Val...

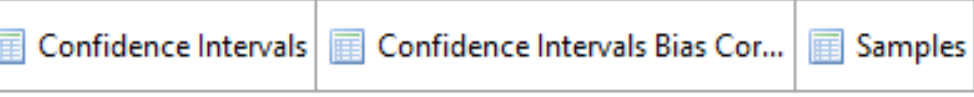

$\begin{array}{lllll}\text { Original Sampl... Sample Mean (... } & \text { Standard Error ... } & \text { T Statistics }(\mid \mathrm{O} \ldots & \text { P Values }\end{array}$

\begin{tabular}{|c|c|c|c|c|c|}
\hline Financial Litera... & 0.912 & $\theta$ & 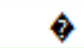 & & \\
\hline Performance & 0.819 & $\theta$ & $\theta$ & & \\
\hline Sustainability & 0.943 & 0.935 & 0.076 & 12.382 & 0.000 \\
\hline
\end{tabular}

\section{Average Variance Extracted (AVE) \\ Average Variance Extracted (AVE)}

\begin{tabular}{|c|c|c|c|c|c|c|}
\hline \multicolumn{2}{|c|}{ Mean, STDEV, T-Values, P-Val... } & \multicolumn{2}{|c|}{ Confidence Intervals } & \multicolumn{2}{|c|}{ Confidence Intervals Bias Cor... } & \multirow{2}{*}{$\begin{array}{c}\text { Samples } \\
\text { P Values }\end{array}$} \\
\hline & Original Sampl... & Sample Mean (... & Stan & dard Error ... & T Statistics (|O... & \\
\hline Financial Litera.... & 0.506 & $\theta$ & & $\theta$ & & \\
\hline Performance & 0.442 & $\geqslant$ & & $\vartheta$ & & \\
\hline Sustainability & 0.847 & 0.844 & & 0.091 & 9.324 & 0.000 \\
\hline
\end{tabular}

\section{Path Coefficients Histogram}

Path Coefficients Histogram

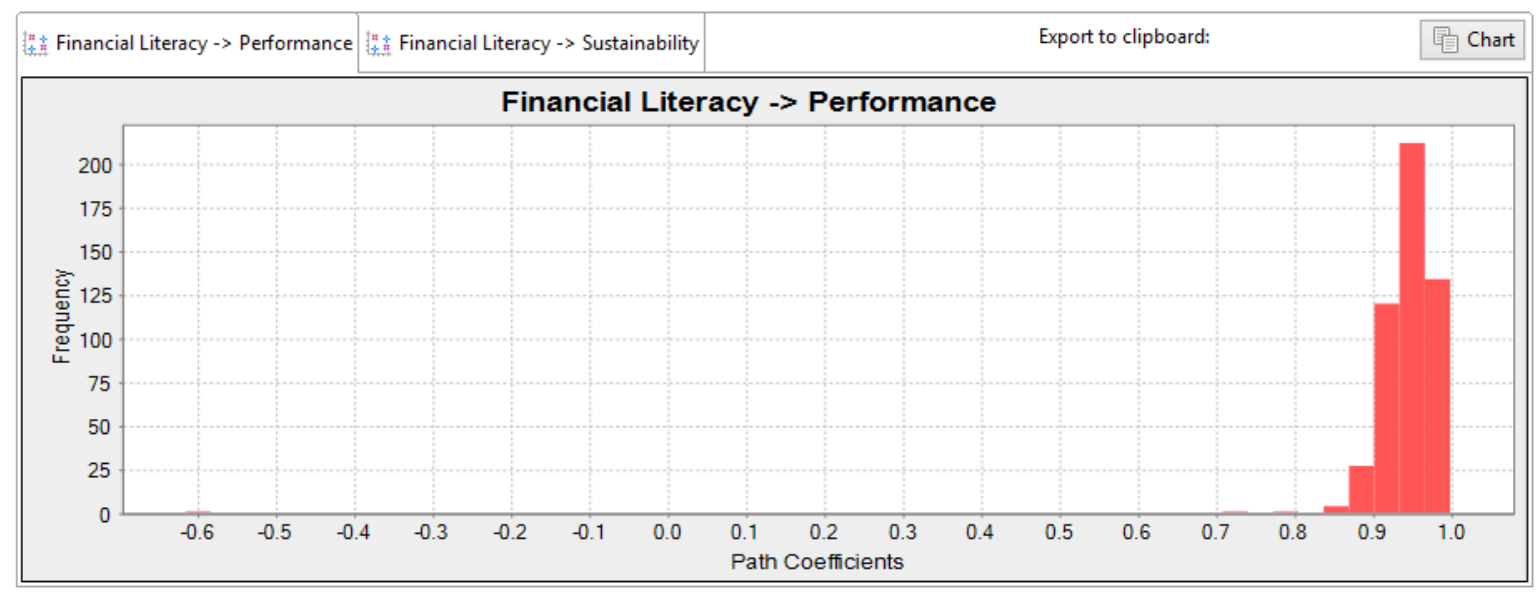


LAMPIRAN 2: Klasifikasi Variabel dan Validitas

\begin{tabular}{cccc}
\hline Item & Keterangan & Klasifikasi & Validity \\
\hline FL1 & ID Card & F1 & Yes \\
FL2 & Initial Deposit & F1 & Yes \\
FL3 & Minimum Balance & F1 & Yes \\
FL4 & Guarantee & F1 & Yes \\
FL5 & Knowledge about Simple & F3 & Yes \\
& Interest & & \\
FL6 & Knowledge about Compound & F3 & Yes \\
& Interest & & \\
FL7 & Knowledge about loan interest & F2 & Yes \\
FL8 & Knowledge about Discount & F2 & Yes \\
FL9 & Knowledge about Inflation & F2 & Yes \\
FL10 & Knowledge about Time Value & F2 & Yes \\
& of Money & & \\
FL11 & Knowledge about Money & F3 & Yes \\
& Illusion & & \\
Pef1 & Planning & Performance & Yes \\
Pef2 & Defect & Performance & Yes \\
Pef3 & Sales & Performance & Yes \\
Pef4 & Cost & Performance & No \\
Pef5 & Anticipation & Performance & Yes \\
Pef6 & Quality & Performance & Yes \\
Pef7 & Reliability & Performance & Yes \\
Sust1 & Payback & Sustainability & Yes \\
Sust2 & Customers & Sustainability & Yes \\
Sust3 & Employees & Sustainability & Yes \\
\hline
\end{tabular}

